\title{
A short review on the modeling of solid-oxide fuel cells by using computational fluid dynamics: assumptions and boundary conditions
}

\author{
Nurul Ashikin Mohd Nazrul Aman ${ }^{1}$, Andanastuti Muchtar ${ }^{1,2, *}$, Mahendra Rao \\ Somalu ${ }^{1}$, Masli Irwan Rosli ${ }^{3}$, Nurul Akidah Baharuddin ${ }^{1}$, Noor Shieela Kalib ${ }^{1,4}$
}

\author{
${ }^{1}$ Fuel Cell Institute, Universiti Kebangsaan Malaysia, 43600 UKM Bangi, Selangor, Malaysia \\ ${ }^{2}$ Centre for Materials Engineering and Smart Manufacturing (MERCU), Faculty of Engineering and Built Environment, \\ Universiti Kebangsaan Malaysia, 43600 UKM Bangi, Selangor, Malaysia \\ ${ }^{3}$ Centre for Sustainable Process Technology (CESPRO), Faculty of Engineering and Built Environment, Universiti \\ Kebangsaan Malaysia, 43600, UKM, Bangi, Selangor, Malaysia \\ ${ }^{4}$ School of Engineering and Physical Sciences, Heriot-Watt University Malaysia, Precinct 5, 62200 Putrajaya, Malaysia
}

Received 26 July 2018; accepted 27 August 2018; available online 30 October 2018

\begin{abstract}
Performance tests are vital for the development of solid-oxide fuel cells (SOFCs) and can help determine the potential of developed SOFCs. However, the challenges in performing these tests such as cost, time, and safety limit the development of SOFCs. Computational fluid dynamics (CFD) can be used to numerically predict the performance of developed SOFCs. CFD methods enable the exploration of many design and operational parameters that are difficult to assess experimentally. This paper focuses on the assumptions and boundary conditions used to model the SOFC stack by using a CFD method. Through the discussions, we briefly explain several assumptions that are commonly found in SOFC modeling. These assumptions are important because they can influence the modeling processes and parameters required for simulations. The boundary conditions required for SOFC modeling are then described to provide an overview on how SOFC operations are incorporated into the model and simulations. Our results can help elucidate the significance of assumptions and boundary conditions used in the CFD modeling of SOFCs
\end{abstract}

Keywords: Solid oxide fuel cells (SOFCs), simulation modeling, computational fluid dynamics (CFD), assumptions, boundary conditions

\section{Introduction}

Renewable energy is currently a hot topic in the energy field. Researchers are paying attention to the renewable and hybrid (combination of renewable and conventional) technologies that can mitigate the increase of power demand that is not parallel to the reduction of fossil fuels and coal that are mainly used in power generation $[1,2]$. Among the various fuels for renewable energy, hydrogen remains widely popular as it can be extracted from abundant resources such as water and biomass. Using hydrogen and light hydrocarbon as fuel in electrical power generation has made solid oxide fuel cell (SOFC) an interesting technology for future power generation. Solid-oxide fuel cells (SOFCs) are energy-conversion devices that use solid ceramic electrolytes to convert energy from chemical reactions to useful electrical energy. The main feature of SOFCs is that they can operate at high temperatures ranging from $600{ }^{\circ} \mathrm{C}$ to 1000 ${ }^{\circ} \mathrm{C}$; this property confers SOFCs with a high efficiency of almost $60 \%$ [1-3]. However, testing SOFC performance is difficult because of their aforementioned high operating temperatures, as well as the required high cost and energy [6]. Moreover, due to operation commonly involving hydrogen $(\mathrm{H})$ and air as fuels, safety risk is also a concern in testing SOFC performance due to the risky handling and storage of $\mathrm{H}$ gas. Results of performance tests are also not always positive. Nevertheless, performance tests are vital to determine the feasibility of newly developed materials for SOFC components or the operational setting applied to SOFC stack. Accordingly, computational fluid dynamics (CFD) is currently receiving considerable attention due to its ability to predict SOFC performance through simulations. CFD is an influential tool in SOFC development because numerous parameters can be simulated and tested. Understanding the interactions among each parameter and their effects on SOFC performance is important. Given the endless possibilities in designing an SOFC stack, an efficient tool that can reduce cost and time requirements is a must in SOFC research [5,6].

CFD coupled with fluid flow, heat transfer, and electrochemical reactions are used to obtain the current or voltage output of a stack. Although the steps in SOFC 
modeling are almost the same regardless of the CFD software used, the results may not be identical because each model is unique. However, similar results can be obtained if the same basic properties such assumptions and boundary conditions are followed. This paper discusses the assumptions and boundary conditions that are commonly used in SOFC modeling by using CFD. Assumptions made for SOFC models are important to reduce computational costs. Moreover, proper assumptions can solve the problems optimally and provide a reliable result. Meanwhile, boundary conditions are set based on the working principle of the SOFC, so most CFD modeling and simulations have similar boundary conditions. Additional boundary conditions may be needed though if different assumptions are made. The next section of this paper briefly discusses the revision of the working principle of the SOFC to aid further discussions on assumptions and boundary conditions used to model an SOFC stack through CFD.

\section{SOFC operation}

Most SOFCs work with $\mathrm{H}$ and air as fuels. Other types of gases such as synthetic gas, biogas, and hydrocarbon gas can also be used in SOFC operation [9]. This paper mainly focuses on SOFCs operating with hydrogen $(\mathrm{H})$ and air as fuels. Generally, a single SOFC stack consist of an electrolyte, a pair of electrodes (anode and cathode), and a pair of interconnect on each electrode's side (Figure 1) [8,9]. The electrolyte, acting as the heart of the SOFC, allows only ionic transport and blocks electron transport. The electrodes act as the redox reaction sites whereas the interconnects act as the support and gas channel for the stack. In normal SOFC operation, $\mathrm{H}$ is supplied to the anode surface and air is supplied to the cathode surface. Voltage is applied to the cathode interconnect surface to facilitate oxygen $(\mathrm{O})$ reduction at the cathode. From this reaction, $\mathrm{O}$ in air reacts with electrons to form $\mathrm{O}$ ions, which then pass through the electrolyte and reach the triple-phase boundary (TPB) near the anode. Afterwards, the oxidized $\mathrm{H}$ at the anode combines with an $\mathrm{O}$ ion, thereby producing water and electron. The electrons are transported via the external circuit, producing useful electricity [10,11]. Figure 2 shows the working principle of a single SOFC stack fueled with $\mathrm{H}$ and air.

Although the working principle of the SOFC is relatively simple to understand, the actual transport processes and electrochemical reactions occurring during SOFC operation are very complex to discuss and solve because everything is inter-related [14]. To address these issues, numerous differential equations are needed, including those related to mass transport, momentum conservation, heat transfer, chemical reactions, and electrochemical equations $[12,13]$. With the currently available CFD commercial software, these equations can be solved numerically. However, for any CFD modeling and simulations, assumptions and boundary conditions are required. Assumptions reduce the computational effort, whereas boundary conditions are compulsory to solve all the equations. Some of these equations are represented in Table 1 to give better picture on the importance of appropriate assumptions and boundary conditions to solve the SOFC problem. The next section discusses the general assumptions and boundary conditions used to model an SOFC stack through a CFD method.

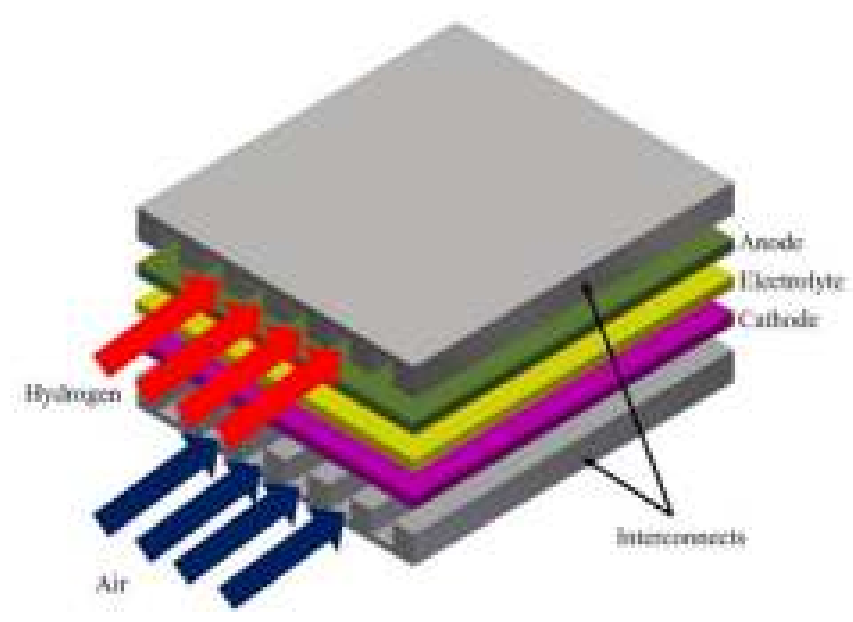

Fig. 1: Assembly of a single SOFC stack

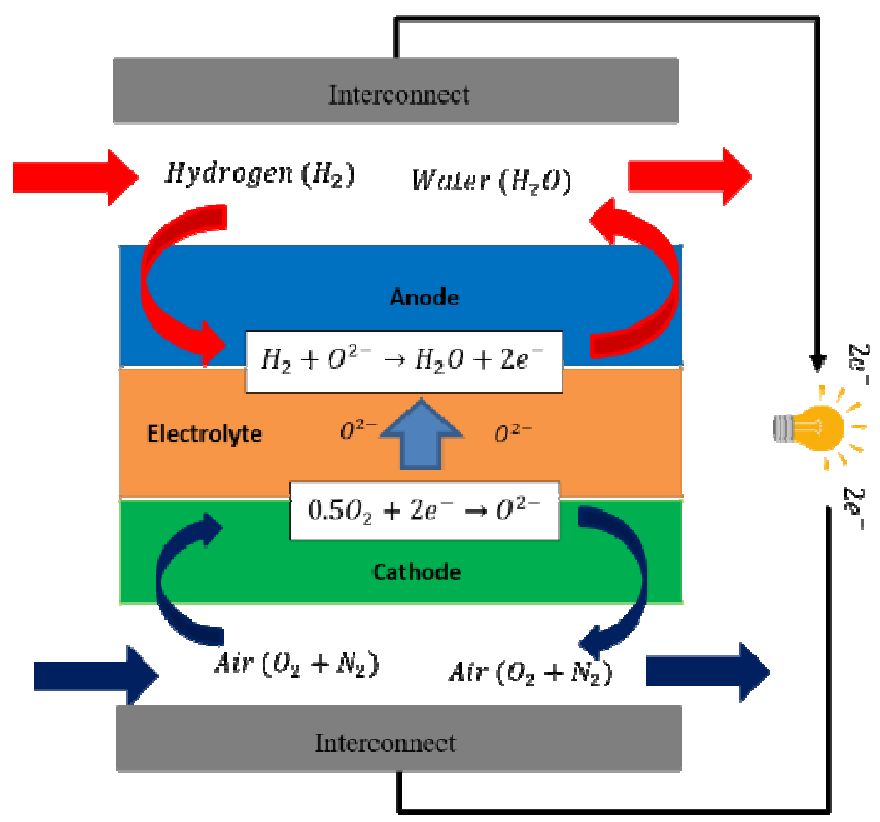

Fig. 2: Working principle of a single SOFC stack

Table 1. Conservation equations required to solve SOFC problems $[15,16]$

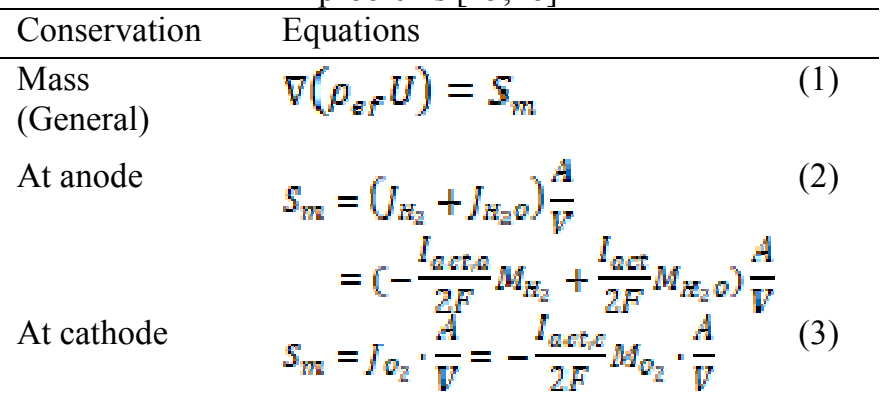




\begin{tabular}{|c|c|}
\hline $\begin{array}{l}\text { Momentum } \\
\text { (Navier-Stokes) }\end{array}$ & $\begin{array}{l}\nabla\left(\rho_{e f} U U\right)=-\nabla P+\nabla\left(\mu_{e f} \nabla U\right)+ \\
S=\frac{-\mu_{e f} U}{U}\end{array}$ \\
\hline Heat & $\nabla\left(\rho_{e f} c_{p g f} U T\right)=\nabla\left(k_{e f} V T\right)+S_{T}$ \\
\hline Species & $\nabla\left(\rho_{e f} U Y_{i}\right)=\nabla\left(D_{i, f f} \nabla Y_{i}\right)+s_{s_{i}, i}$ \\
\hline Charge & $-\nabla\left(\sigma_{e f} \nabla \Phi\right)=s_{\omega}$ \\
\hline Electrochemical & $E_{o c v}=E^{0}-\frac{R T}{\eta F} \ln \left(\frac{p_{H_{2} O}}{p_{n}}\right)$ \\
\hline
\end{tabular}

Where:

\begin{tabular}{|c|c|}
\hline$P_{\theta f}$ & $\begin{array}{l}\text { : effective density } \\
\text { : velocity vector }\end{array}$ \\
\hline$s_{m}, s_{i t}, s_{T}, s_{s i}$ & $\begin{array}{l}\text { : source term for mass, diffusion, heat } \\
\text { and species }\end{array}$ \\
\hline $\mathrm{J}$ & : mass absorption flux \\
\hline$I_{\text {act }}$ & $\begin{array}{l}\text { : transfer current density of the } \\
\text { reactions at the electrodes }\end{array}$ \\
\hline$I_{\text {act }}$ & $\begin{array}{l}\text { : current density for reactions at the } \\
\text { electrode }\end{array}$ \\
\hline$M$ & molecular weight \\
\hline & active surface area for the reactions \\
\hline 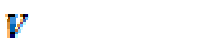 & controlled volume for the reactions \\
\hline
\end{tabular}

\section{Assumptions in SOFC modeling}

Several pieces of information are required to model SOFCs through CFD; they include the types of problem needed to be solved, materials and fluid properties required to solve the problems, boundary conditions that govern SOFC operations, initial conditions that should be applied to expedite the solution processes, and solver settings used to solve the problems numerically. However, the most important data required to model SOFC stack are the related assumptions and boundary conditions. Assumptions affect the boundary conditions and other parameters used in the modeling, whereas boundary conditions are required to solve the equations involved. Unlike assumptions and boundary conditions, initial conditions and solver setting can be set according to suitability of the CFD software used. Their roles are focused on speeding up convergence for numerical solutions. For SOFC operation, the real transport processes are yet to be fully explained as the they are difficult to be observed and measured experimentally [19]. Therefore, proper assumptions are required to solve the problem. These assumptions are bound to change as more information on the transport processes are obtained from the experiments. In addition, the assumptions made for single SOFC stack operation can be different from that of multiple SOFC stacks operation. However, in this paper, the assumptions discussed are focusing on the single SOFC stack operation.

In single-SOFC-stack operations, the transport problems that must be solved to obtain the voltage or current input of the stacks are fluid flow, electrochemical reactions (chemistry and electrical), and heat transfer. After defining the transport processes occurring during the SOFC operation, appropriate assumptions must be made accordingly to solve the problem optimally at reduced computational cost albeit with acceptable results. 5) Given that CFD solves fluid dynamics, assumptions on (6) fluid flow are very important. In SOFCs, gas flow can be viewed as flow in pipe (for gas flow in channels) and flow of fluid across porous materials (for gas diffusion across electrodes). Generally, for SOFC modeling, the assumptions made for the flow are as follows: the flow is laminar and incompressible, and gases behave as ideal gases [20]. Laminar and incompressible flow assumptions are made because flow velocity in an SOFC operation, as well as the pressure drop across the channel, is very small $[18,19]$. Therefore, these assumptions are appropriate for SOFC modeling. These assumptions limit the flow velocity at the inlets. To ensure that these assumptions are valid, the Reynold number for gas inlet velocity is limited to lower than 2300. Otherwise, turbulent flow should be considered to address the flow related equations [23]. The fuels used in the SOFC stack $\left(\mathrm{O}_{2}, \mathrm{H}_{2}, \mathrm{H}_{2} \mathrm{O}, \mathrm{N}_{2}\right)$ are originally real gases. However, at high temperatures $\left(>477^{\circ} \mathrm{C}\right)$, these gases exhibit relatively low densities and behave like ideal gases [24]. Therefore, the ideal gas assumption can be used to simplify the SOFC transport problems. In addition, ideal-gas assumption also simplifies most of the fluid-related equations required to be solved by CFD and thus reduces the computational time. In addition, steady-state assumption is usually used in modeling SOFC operation to reduce the complexity of equations due to time-derivative parameters. Another assumption made to the SOFC flow is that the product of the chemical reactions at the anode side $\left(\mathrm{H}_{2} \mathrm{O}\right)$ remains as gas phase

For heat transfer, the assumption commonly made is that the radiation effect in the stack is negligible [16]. Considering that heat transfer occurring in SOFC is significantly in conduction or convection mode, the effect of radiation is usually not considered during simulation, especially in planar SOFCs as the amount is comparatively smaller [22-26]. Moreover, in single planar SOFC, heat radiation does not affect the cell. Another factor causing the radiation to be neglected in modeling is the limitation of radiation parameters from literature especially for the new materials. With enough data to simulate radiation, it is possible to address the radiation effect in SOFC operation [30]. However, in single tubular SOFC, the radiation effect is taken into consideration during modeling [31]. Additionally, when thermal stresses are to be studied, the effect of radiation has to be considered especially for multiple stacks model as there are surface to surface contacts between the stacks that make the radiation effect significant $[29,30]$. Another common assumption made to simplify the heat-transfer problem in SOFC stack is that, the temperature of gases at the outlets are the same as those in the inlets. This assumption is made due to the nature of the single SOFC attack performance testing that is usually conducted in a closed oven or furnace [34]. Accordingly, the initial temperature within the stack is set with the same operating temperature. Another assumption made regarding heat-transfer problem in SOFC modeling is that 
local temperature equilibrium (LTE) approach is used to solve the temperature change within a single stack. This approach assumes that the temperature of the solid and gas phases within the electrodes are locally the same [35], [36]. The succeeding section discusses the boundary conditions commonly required to model an SOFC stack.

\section{Boundary conditions required for SOFC modeling}

After proper assumptions are made for an SOFC model, the boundary conditions for the model need to be determined. Although transport problems within the SOFC stack are to be solved numerically by CFD software, compliant boundary conditions should be set prior to simulation. Boundary conditions are very important in CFD simulation because they direct the motions of the flow. A basic geometric model of a single SOFC stack is usually similar to the one shown in Figure 1. However, in some SOFC models, the electrodes (anode and cathode) are split into two layers, i.e., the diffusion and active layers where gas diffusion and chemical reactions occur, respectively [13-15]. The only difference among these geometric models is the location of chemical reactions. When the SOFC stack geometry consists of a single layer for each anode and cathode, the chemical reaction can be set at the electrodes but when diffusion and active layers are present, the electrochemical reactions are set to occur at the active layers. The important boundary conditions in the SOFC model include inlets, outlets, wall, voltage or current input, surface reaction mechanisms, gas properties (mass or molar fractions), and temperature setting.

The inlets of an SOFC stack are set at one end of the gas channels, whereas the outlets are set at the other end of the gas channel. At the inlets, the type of gas to be supplied is set, i.e., $\mathrm{H}$ at the inlets near the anode and air at the inlets near the cathode. Other parameters required for inlets are gas flow rate or velocity, mass or molar fractions of the gases, and temperature of gases entering the SOFC stack. As for the velocity or flow rate set at the inlets, the value must obey laminar Reynold number for flow in pipes. Huang et al. (2008) suggested that the Reynold number for $\mathrm{H}$ flow at the anode should range from 20 to 50 while for air flow at the cathode, the value is somewhere around 200 to 300 for reasonable power density, good fuel utilization, and effective heat removal [23]. Meanwhile, the outlets of the stack are usually set as fixed pressure outlets with atmospheric pressure $[13,24,29]$. Apart from a fixed pressure condition, there is research that considered convective flux condition at the outlet $[6,15]$. These outlet boundary conditions are chosen based on the outlet type selections supported by the CFD software. The parameters required at the outlet is the temperature and pressure of gases exiting the stack. The walls for the SOFC stack geometry are set to adiabatic, except for the anode and cathode contact surfaces that are set to isothermal with initial temperature equal to that of operating temperature [37]. At the electrode contacts, voltage or current is set according to the real SOFC performance test setup (operating voltage or current density). Table 2 summarizes the boundary conditions discussed, together with the parameters that are commonly set for SOFC modeling. These boundary condition lists are based on the common SOFC simulation modeling and can be changed according to the assumptions made. If the number of assumptions made for the model are increased or decreased, then the number of boundary condition parameters can also increase or decrease.

Table 2. Boundary conditions required for SOFC modeling [14,35]

\begin{tabular}{|c|c|c|}
\hline $\begin{array}{l}\text { Boundary } \\
\text { conditions }\end{array}$ & Parameters & Reference value \\
\hline \multirow[t]{3}{*}{ Inlets } & $\begin{array}{l}\text { Mass flow rate } \\
\text { or velocity }\end{array}$ & $\operatorname{Re}<2300$ (flow in pipe) \\
\hline & $\begin{array}{l}\text { Mass or molar } \\
\text { fractions of the } \\
\text { gases }\end{array}$ & $\begin{array}{l}\text { Depending on the fuel } \\
\text { used }\end{array}$ \\
\hline & Temperature & $\begin{array}{l}\text { Same as operating } \\
\text { temperature }\end{array}$ \\
\hline \multirow[t]{2}{*}{ Outlets } & $\begin{array}{l}\text { Reference } \\
\text { pressure } \\
\text { (usually set as } \\
1 \text { atm) }\end{array}$ & $1 \mathrm{~atm}$ \\
\hline & Temperature & $\begin{array}{l}\text { Same as operating } \\
\text { temperature }\end{array}$ \\
\hline $\begin{array}{l}\text { Anode } \\
\text { contact }\end{array}$ & Temperature & $\begin{array}{l}\text { Same as operating } \\
\text { temperature }\end{array}$ \\
\hline \multirow[t]{2}{*}{$\begin{array}{l}\text { Cathode } \\
\text { contact }\end{array}$} & Temperature & $\begin{array}{l}\text { Same as } \\
\text { temperature }\end{array}$ \\
\hline & $\begin{array}{l}\text { Voltage or } \\
\text { current applied }\end{array}$ & - \\
\hline Cathode & $\begin{array}{l}\text { Surface } \\
\text { reaction } \\
\text { mechanism }\end{array}$ & $0.50_{2}+2 \mathrm{e}^{-} \rightarrow 0^{2^{-}}$ \\
\hline Anode & $\begin{array}{l}\text { Surface } \\
\text { reaction } \\
\text { mechanism }\end{array}$ & $\mathrm{H}_{2}+\mathrm{O}^{2-} \rightarrow \mathrm{H}_{2} \mathrm{O}+2 \mathrm{e}^{-}$ \\
\hline
\end{tabular}

\section{Conclusion}

Modeling an SOFC stack by using the CFD method is very convenient because this method can help explore the potential of many design and operational parameters within a short time at a low cost. However, the working principle of the SOFC and how CFD solves the problems within the SOFC stack should be known beforehand to ensure that the parameters and conditions set for modeling afterwards are appropriate and conform to those of real SOFCs. Compared with other steps in CFD modeling and SOFC simulations, assumptions and boundary conditions play significant roles in addressing the problem accurately and optimally. Accordingly, in this work, we highlighted the general or commonly used assumptions and boundary conditions to provide improved insight into the important information and 
parameters that must be prepared during SOFC modeling. These two components of SOFC modeling are very important and must be addressed appropriately when using the CFD method to ensure that the outputs of the model simulations are comparable to experimental outputs. This step very important because the disparity between both outputs determines the reliability of the developed models. For future works, initial conditions and solver selection used for SOFC modeling by using CFD can be discussed to reduce the computational effort for simulations and to obtain solution convergence.

\section{Acknowledgement}

The authors would like to thank Universiti Kebangsaan Malaysia (UKM) for their support in the project funding through research grant GUP-2016-45.

\section{References}

[1] Ebshish, A., Yaakob, Z., Narayanan, B., Bshish, A., Ramli, W., and Daud, W. The activity of Nibased catalysts on steam reforming of glycerol for hydrogen production. International Journal of Integrated Engineering, Volume 3, (2011), pp. 58.

[2] Raheem, A., Hassan, M. Y., and Shakoor, R. Economic feasibility of stand-alone wind energy hybrid with bioenergy from anaerobic digestion for electrification of remote area of Pakistan. International Journal of Integrated Engineering, Volume 6, (2014), pp. 1-8.

[3] Facci, A. L. ,Cigolotti, V., Jannelli, E., and Ubertini, S. Technical and economic assessment of a SOFC-based energy system for combined cooling, heating and power. Applied Energy, Volume 192, (2017), pp. 563-574.

[4] Marco, V. D. E., Iannaci, A., Rashid, S., and Sglavo,V. M. Performance and evolution of planar copper-based anode-supported solid oxide fuel cells. Journal of the Ceramic Society of Japan, Volume 4, (2017), pp. 313-316.

[5] Shaikh, S. P. S., Muchtar, A., and Somalu, M. R. A review on the selection of anode materials for solid-oxide fuel cells. Renewable and Sustainable Energy Reviews, Volume 51, (2015), pp. 1-8.

[6] Andersson, M., Yuan, J., and Sundén, B. SOFC modeling considering hydrogen and carbon monoxide as electrochemical reactants. Journal of Power Sources, Volume 232, (2013), pp. 4254.

[7] Pianko-Oprych, P., Zinko, T., and Jaworski, Z. CFD modelling of hydrogen starvation conditions in a planar Solid Oxide Fuel Cell. Polish Journal of Chemical Technology, Volume 19, (2017), pp. 16-25.

[8] Li, A., Song, C., and Lin, Z. A multiphysics fully coupled modeling tool for the design and operation analysis of planar solid oxide fuel cell stacks. Applied Energy, Volume 190, (2017), pp.
1234-1244.

[9] Mahmud, L. S., Muchtar, A., and Somalu, M. R. Challenges in fabricating planar solid oxide fuel cells: A review. Renewable and Sustainable Energy Reviews, Volume 72, (2017), pp. 105116.

[10] Mah, J. C. W., Muchtar, A., Somalu, M. R., and Ghazali, M. J. Metallic interconnects for solid oxide fuel cell: A review on protective coating and deposition techniques. International Journal of Hydrogen Energy, Volume 42, (2017), pp. 9219-9229.

[11] Anwar, M., Muchtar, A., and Somalu, M. R. Effects of Various Co-Dopants and Carbonates on the Properties of Doped Ceria-Based Electrolytes: A Brief Review. International Journal of Applied Engineering Research ISSN, Volume 11, (2016), pp. 973-4562.

[12] Yang, S., Chen,T., Wang, Y., Peng, Z., and Wang, W. G. Electrochemical analysis of an anode-supported SOFC. International Journal of Electrochemical Science, Volume 8, (2013), pp. 2330-2344.

[13] Baharuddin, N. A., Muchtar, A., and Somalu, M. R. Short review on cobalt-free cathodes for solid oxide fuel cells. International Journal of Hydrogen Energy, Volume 42, (2017), pp. 91499155.

[14] Li, J., Bai, Z., and Croiset, E. A two-dimensional modeling of solid oxide fuel cell button cells with detailed electrochemistry mechanism. Journal of Power Sources, Volume 333, (2016), pp. 164172.

[15] Zhang, Z. et al. Three-Dimensional CFD Modeling of Transport Phenomena in a CrossFlow Anode-Supported Planar SOFC. Energies, Volume 7, (2014), pp. 80-98.

[16] Nishida, R. T., Beale, S. B., Pharoah, J. G., Haart, L. G. J. de, and Blum, L.Threedimensional computational fl uid dynamics modelling and experimental validation of the Jülich Mark-F solid oxide fuel cell stack. Journal of Power Sources, Volume 373, (2018), pp. 203210.

[17] Zhang, Z. et al.Three-dimensional CFD modeling of transport phenomena in multi-channel anodesupported planar SOFCs. International Journal of Heat and Mass Transfer, Volume 84, (2015), pp. 942-954.

[18] Ighodaro, O. O., Scott, K., and Xing, L. An Isothermal Study of the Electrochemical Performance of Intermediate Temperature Solid Oxide Fuel Cells. Journal of Power and Energy Engineering, Volume 5, (2017), pp. 97-122.

[19] Tseronis, K., Bonis, I., Kookos, I. K., and Theodoropoulos,C. Parametric and transient analysis of non-isothermal, planar solid oxide fuel cells. International Journal of Hydrogen Energy, Volume 37, (2012), pp. 530-547.

[20] Dey, T., Singdeo, D., Basu, R. N., Bose, M., and 
Ghosh, P. C. Improvement in solid oxide fuel cell performance through design modifications: An approach based on root cause analysis. International Journal of Hydrogen Energy, Volume 39, (2014), pp. 17258-17266.

[21] Hosseini, S., Ahmed, K., and Tadé, M. O. CFD model of a methane fuelled single cell SOFC stack for analysing the combined effects of macro/micro structural parameters. Journal of Power Sources, Volume 234, (2013), pp. 180196.

[22] Chinda, P., Chanchaona, S., and Brault, P. A Planar Anode - Supported Solid Oxide Fuel Cell Model with Internal Reforming of Natural Gas. European Physical Journal:Applied Physics, EDP Sciences, , (2011), .

[23] Huang, C. M., Shy, S. S., and Lee, C. H. On flow uniformity in various interconnects and its influence to cell performance of planar SOFC. Journal of Power Sources, Volume 183, (2008), pp. 205-213.

[24] Shekaari, A. and Jafari, M.Effect of pairwise additivity on finite-temperature behavior of classical ideal gas. Physica A: Statistical Mechanics and its Applications, Volume 497, (2018), pp. 101-108.

[25] Jeon, D. H. A comprehensive CFD model of anode-supported solid oxide fuel cells. Electrochimica Acta, Volume 54, (2009), pp. 2727-2736.

[26] Tseronis, K., Fragkopoulos, I. S., Bonis, I., and Theodoropoulos, C. Detailed Multi-dimensional Modeling of Direct Internal Reforming Solid Oxide Fuel Cells. Fuel Cells, Volume 16, (2016), pp. 294-312.

[27] Razbani, O., Assadi, M., and Andersson, M. Three dimensional CFD modeling and experimental validation of an electrolyte supported solid oxide fuel cell fed with methanefree biogas. International Journal of Hydrogen Energy, Volume 38, (2013), pp. 10068-10080.

[28] Yang, Y., Du, X., Yang, L., Huang, Y., and Xian, $H$. Investigation of methane steam reforming in planar porous support of solid oxide fuel cell. Applied Thermal Engineering, Volume 29, (2009), pp. 1106-1113.

[29] Chinda, P. S. and Chanchaona, P Brault, and Wechsatol, W. A Planar Anode - Supported Solid Oxide Fuel Cell Model with Internal Reforming of Natural Gas. Applied Physics, Volume 54, (2011), pp. 15-39.

[30] Tran, D. L., Tran,Q. T., Sakamoto, M., Sasaki, K., and Shiratori, Y. Modelling of CH4 multiplereforming within the Ni-YSZ anode of a solid oxide fuel cell. Journal of Power Sources, Volume 359, (2017), pp. 507-519.

[31] Pianko-Oprych, P., Zinko, T., and Jaworski, Z. Simulation of thermal stresses for new designs of microtubular Solid Oxide Fuel Cell stack. International Journal of Hydrogen Energy,
Volume 40, (2015), pp. 14584-14595.

[32] Wei, S. S., Wang, T. H., and Wu, J. S. Numerical modeling of interconnect flow channel design and thermal stress analysis of a planar anodesupported solid oxide fuel cell stack. Energy, Volume 69, (2014), pp. 553-561.

[33] García-Camprubí, M., Izquierdo, S., and Fueyo, $\mathrm{N}$. Challenges in the electrochemical modelling of solid oxide fuel and electrolyser cells. Renewable and Sustainable Energy Reviews, Volume 33, (2014), pp. 701-718.

[34] Goldin, G. M., Zhu, H., Kee, R. J., Bierschenk, D., and Barnett, S. A. Multidimensional flow, thermal, and chemical behavior in solid-oxide fuel cell button cells. Journal of Power Sources, Volume 187, (2009), pp. 123-135.

[35] Khazaee, I. and Rava, A. Numerical simulation of the performance of solid oxide fuel cell with different flow channel geometries. Energy, Volume 119, (2017), pp. 235-244.

[36] Andersson, M., Paradis, H., Yuan, J., and Sunden, B. Three dimensional modeling of an solid oxide fuel cell coupling charge transfer phenomena with transport processes and heat generation. Electrochimica Acta, Volume 109, (2013), pp. 881-893.

[37] Lin, B., Shi, Y., and Cai, N. Numerical simulation of cell-to-cell performance variation within a syngas-fuelled planar solid oxide fuel cell stack. Applied Thermal Engineering, Volume 114, (2017), pp. 653-662.

[38] Pianko-oprych, P. and Zinko, T. Simulation of the steady-state behaviour of a new design of a single planar Solid Oxide Fuel Cell. Polish Journal of Chemical Technology, Volume 18, (2016), pp. 64-71. 